\title{
Decreased 1,25-Dihydroxyvitamin $D_{3}$ Receptor Density is Associated with a More Severe Form of Parathyroid Hyperplasia in Chronic Uremic Patients
}

\author{
Naoko Fukuda, Hiroyuki Tanaka, Yoshihiro Tominaga, Masafumi Fukagawa, Kiyoshi Kurokawa, and Yoshiki Seino \\ Department of Pediatrics, Okayama University Medical School, Okayama 700, Japan; Department of Transplant Surgery, \\ Nagoya Second Red Cross Hospital, Showa-ku, Nagoya 466, Japan; and First Department of Internal Medicine, \\ Faculty of Medicine, University of Tokyo, Bunkyo-ku, Tokyo 113, Japan
}

\begin{abstract}
The resistance of parathyroid cells to 1,25-dihydroxyvitamin $\mathrm{D}_{3}\left(1,25(\mathrm{OH})_{2} \mathrm{D}_{3}\right)$ in uremic hyperparathyroidism is thought to be caused, in part, by a $1,25(\mathrm{OH})_{2} \mathrm{D}_{3}$ receptor (VDR) deficiency in the parathyroids. However, results of biochemical studies addressing VDR numbers in the parathyroids are controversial. Several studies have found VDR content to be decreased in the parathyroids of uremic patients and animals, while others have found no such decrease in the parathyroids of uremic animals.

To clarify the role of VDR, we investigated VDR distribution in surgically-excised parathyroids obtained from chronic dialysis patients by immunohistochemistry. We classified the parathyroids as exhibiting nodular or diffuse hyperplasia. Our studies demonstrated a lower density of VDR in the parathyroids showing nodular hyperplasia than in those showing diffuse hyperplasia. Even in the parathyroids showing diffuse hyperplasia, nodule-forming areas were present; these areas were virtually negative for VDR staining. A significant negative correlation was found between VDR density and the weight of the parathyroids. These findings indicate that the conflicting results of biochemical studies may be caused by the heterogeneous distribution of VDR; the decreased VDR density in parathyroids may contribute to the progression of secondary hyperparathyroidism and to the proliferation of parathyroid cells that is seen in uremia. (J. Clin. Invest. 1993. 92:1436-1443.) Key words: calcitriol receptor $\bullet$ chronic renal failure $\bullet$ hyperparathyroidism • immunohistochemistry • vitamin D resistance
\end{abstract}

\section{Introduction}

Patients on long-term hemodialysis caused by chronic renal failure commonly have accompanying renal bone disease, one of the major factors underlying this disease being secondary

This work was presented in part in abstract form at the 25th Annual Meeting of the American Society of Nephrology, Baltimore, MD, 1518 November, 1992.

Address correspondence to Y. Seino, Department of Pediatrics, Okayama University Medical School, 2-5-1 Shikata-cho, Okayama 700, Japan.

Received for publication 8 February 1993 and in revised form 26 April 1993.

J. Clin. Invest.

(c) The American Society for Clinical Investigation, Inc.

0021-9738/93/09/1436/08 \$2.00

Volume 92, September 1993, 1436-1443 hyperparathyroidism (2HPT) ${ }^{1}$. Parathyroid hyperplasia and high levels of immunoreactive parathyroid hormone (PTH) are present in the early stage of 2HPT (1). The initial stimulus for the hypersecretion of PTH is thought to be predominantly a chronic reduction of ionized calcium in the extracellular fluid, caused by the reduced production of $1,25(\mathrm{OH})_{2} \mathrm{D}_{3}$ and/or to phosphate retention. Although 2HPT is sometimes managed by calcium supplementation, by maintenance of the physiologic level of serum $1,25(\mathrm{OH})_{2} \mathrm{D}_{3}$ by oral $1,25(\mathrm{OH})_{2} \mathrm{D}_{3}$ therapy, and by restriction of phosphate intake, many patients with 2HPT remain unresponsive to this conservative treatment. Recent studies have suggested that resistance of parathyroid cells to $1,25(\mathrm{OH})_{2} \mathrm{D}_{3}$ might underlie the $2 \mathrm{HPT}$ in uremia (2), and reduction of VDR density is believed to participate in the pathogenesis of this resistance. In fact, some studies have biochemically demonstrated reduced VDR numbers in the parathyroids of uremic patients (3) and animals $(4,5)$. However, other studies have had different results, finding that VDR levels were not decreased in the uremic rats $(6,7)$.

In chronic dialysis patients with $2 \mathrm{HPT}$, the parathyroid glands have been histologically classified into three patterns; those showing adenoma, diffuse hyperplasia, and nodular hyperplasia (8-10). The nodular hyperplasia may represent an advanced stage of hyperplasia and be present in more severe hyperparathyroidism (11). To determine the cause of parathyroid resistance to $1,25(\mathrm{OH})_{2} \mathrm{D}_{3}$ in uremia and the relationship between the progression of 2HPT and the numbers of VDR, we examined VDR density and distribution by histochemical staining. We used a monoclonal antibody against VDR in surgically excised parathyroid glands of the diffuse and nodular hyperplasia.

\section{Methods}

Clinical samples. Tissue specimens were obtained from 16 hemodialysis patients with 2HPT, for which they had total parathyroidectomy with forearm autograft. The duration of hemodialysis before parathyroidectomy was $12.9 \pm 4.5 \mathrm{yr}($ mean $\pm \mathrm{SD})$. Each patient met all the following indications for parathyroidectomy: high serum PTH levels ( $\mathrm{COOH}$-terminal immunoreactive $\mathrm{PTH}>20 \mathrm{ng} / \mathrm{ml}$ ), positive radiologic study for osteitis fibrosa, enlarged parathyroid glands on preoperative image diagnosis, and resistance to medical treatment. The preoperative concentrations of serum calcium and phosphate were $5.2 \pm 0.5$ $\mathrm{meq} /$ liter (normal range: $4.4-5.5 \mathrm{meq} / \mathrm{liter}$ ) and $6.3 \pm 2.0 \mathrm{mg} / 100 \mathrm{ml}$ (normal range: $2.7-4.4 \mathrm{mg} / 100 \mathrm{ml}$ ), respectively. Calcium values were corrected for protein concentration. All patients were treated with

1. Abbreviations used in this paper: $1,25\left(\mathrm{OH}_{2} \mathrm{D}_{3}, 1,25\right.$-dihydroxyvitamin $\mathrm{D}_{3}$; D-type, a type of diffuse hyperplasia; 2HPT, secondary hyperparathyroidism; N-type, a type of nodular hyperplasia; PTH, parathyroid hormone; VDR, 1,25-dihydroxyvitamin $\mathrm{D}_{3}$ receptor. 
alfacalcidol ( 0.25 or $0.5 \mu \mathrm{g}$ daily), and two patients were treated with high dose $1,25(\mathrm{OH})_{2} \mathrm{D}_{3}$ by intermittent oral therapy, but, nevertheless, 2HPT progressed. In total parathyroidectomy with forearm autograft, all parathyroid glands were excised and pieces of parathyroid tissue, taken from the smallest parathyroid gland in each case, were autotransplanted into forearm. These patients were followed for $\geq 1 \mathrm{yr}$; there was no graft-dependent recurrence.

We examined 20 parathyroid glands; all exhibited hyperplasia, not adenoma. The pattern of hyperplasia was divided into two types both macroscopically and microscopically, one type being diffuse (D-type), with a normal lobular constitution (Fig. $1 A$ ), and the other being nodular ( $N$-type)(Fig. $1 B$ ). The criteria for nodular hyperplasia were the presence of at least one well-circumscribed encapsulated nodule and virtually fat cell-free accumulation of parenchymal cells (12). According to these criteria, the 20 parathyroid glands were classified into $14 \mathrm{~N}$-type glands and six D-type. In one patient, two glands, one N-type and one D-type, were excised. In another patient, four parathyroid glands, two N-type and two D-type, were excised. The other 14 glands, 11 N-type and three D-type, were excised from 14 patients; i.e., one gland from each patient. The $11 \mathrm{~N}$-type parathyroid glands were the largest of the glands obtained from each patient.

Surgically-excised specimens were immediately embedded in OCT compound (Miles Inc., Elkhart, IN) and snap frozen in liquid nitrogen.

Immunohistochemistry for $1,25(\mathrm{OH})_{2} \mathrm{D}_{3}$ receptor. Monoclonal an- tibody 9A7 (kindly provided by Dr. J. W. Pike, Department of Pediatrics, Baylor College of Medicine, Houston, TX) was raised against chick intestinal VDR, as described previously (13). Tissue sections ( 5 $\mu \mathrm{m}$ ) were cut on a cryostat (Jung Frigocut 2800 E; Reichert-Jung, Germany, and Bright Cryostat; Bright Instrument Co. Ltd., Huntingdon, England) and thaw-mounted on slides coated with poly-L-lysine (Sigma Immunochemicals, St. Louis, MO). They were immediately fixed in 4\% paraformaldehyde (Nacalai Tesque Inc., Kyoto, Japan) in PBS ( $\mathrm{pH} \mathrm{7.3)} \mathrm{at} 4^{\circ} \mathrm{C}$ for 60 min, followed by three washes with PBS. After the washing, nonspecific reaction was blocked with normal $5 \%$ goat serum (Vector Laboratories, Burlingame, CA) in PBS. Sections from each specimen were immersed in either 9A7 antibody (diluted $1: 1,000$ or $1: 2,000$ in PBS containing $1 \%$ goat serum) or in control solution ( $1 \%$ goat serum in PBS) and incubated overnight at $4{ }^{\circ} \mathrm{C}$. Slides were washed thoroughly in several changes of PBS; $50 \mu$ l or less of diluted gold-conjugated anti-rat IgG (BioCell, Cardiff, CA ) (1/100 in PBS) was then placed on each section and the slides were incubated for $1 \mathrm{~h}$ at room temperature. They were then washed five times with distilled water and a drop of silver-enhancing solution (BioCell) was applied to each specimen. The development of a silver deposit was monitored continuously and the process was stopped, by immediate washing in tap water, when specific staining was complete and the background remained minimal.

The specificity of the staining reaction for VDR was confirmed by

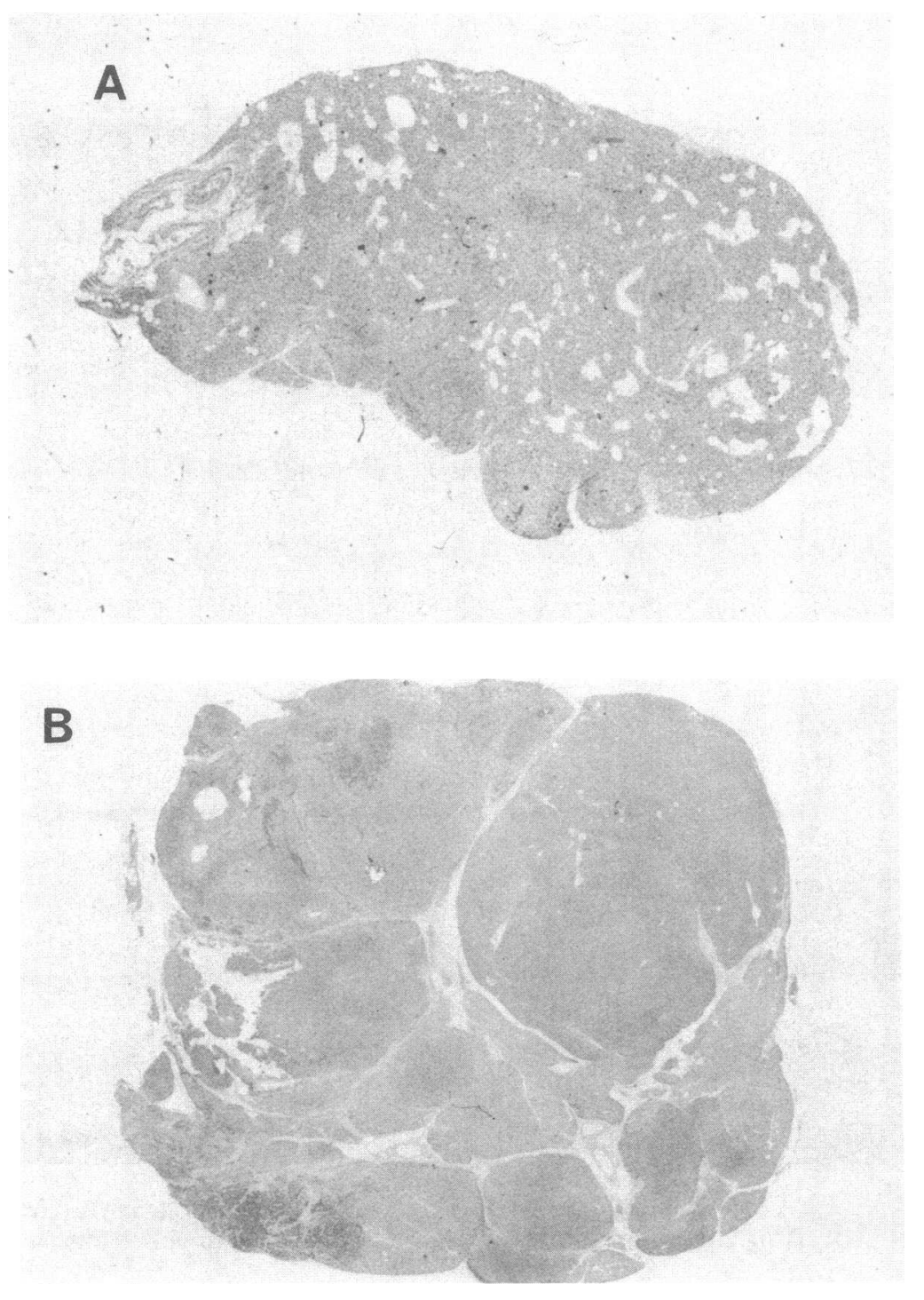

Figure 1. Microphotograph of hyperplastic parathyroid tissue (hematoxylin and eosin stain). $(A)$ Diffuse hyperplasia with normal lobular constitution. $\times 40$. $(B)$ Nodular hyperplasia with several nodules surrounded by fibrous bands. $\times 20$. 
immunostaining studies, using the $9 \mathrm{~A} 7$ monoclonal antibody preabsorbed with recombinant VDR (kindly provided by Dr. J. W. Pike). Recombinant VDR was produced and purified from yeast in a functional form (14). The preabsorption of monoclonal antibody with recombinant VDR was performed at $4^{\circ} \mathrm{C}$ for $18 \mathrm{~h}$ before the staining procedure.

Immunohistochemistry for PTH. Some sections were stained for PTH after the VDR staining, using chicken antibody against rat PTH (Yamasa, Tokyo, Japan), which reacts with human PTH, as described previously (15). After the VDR staining procedure, anti-rat PTH antibody (diluted 1:10,000 in PBS) was mounted on the section and incubated overnight at $4^{\circ} \mathrm{C}$. Slides were washed three times, incubated with biotin-labeled anti-chicken IgG (Vector Laboratories) diluted 1:200 with PBS containing $0.5 \%$ bovine serum albumin (Nacalai Tesque. Inc.) for $30 \mathrm{~min}$ at room temperature, after which they were washed again with PBS three times. The avidin-biotin complex, labeled with glucose oxidase (Vector Laboratories), was mounted on the sections for 30-60 min at room temperature. After being washed with PBS, the sections were finally treated with a glucose oxidase substrate kit (Vector Laboratories) diluted in $50 \mathrm{mM}$ Tris $\mathrm{HCl}$ ( $\mathrm{pH} \mathrm{9.5)} \mathrm{for} \mathrm{15-30} \mathrm{min.}$ Counterstaining was done in $\mathbf{0 . 2 \%}$ methylene green or Mayer's hematoxylin.

Evaluation. Staining of slides incubated with 9A7 was compared with that of control slides without 9A7. The reaction in the section was evaluated as specific when such a reaction was absent in the control section and was inhibited by preincubation of $9 \mathrm{~A} 7$ with recombinant VDR. The percentage of specifically-stained nuclei was estimated. Scoring was performed in at least five high-power magnification (400) fields by two observers. Nuclei were regarded as being stained specifically only when there was agreement between the two observers. Nuclei were counted within nodules in the $\mathrm{N}$-type and the count was excluded in the areas forming small nodules in the D-type. To assess the reproducibility of this staining procedure, one D-type specimen was stained repeatedly; the percentages of positive VDR staining were $44.8,54.5$, 52.3 , and $55.9 \%$ (coefficient of variation, 9.5\%). In addition, some specimens were stained with FITC-conjugated goat anti-rat IgG (Kirkegaard \& Perry Laboratories Inc., Gaithersburg, MD) instead of goldconjugated goat anti-rat IgG as the second antibody; these were analyzed with an interactive laser cytometer (ACAS570; Meridian Instruments Inc., Okemos, MI). The results of this measurement were similar to the results obtained from scoring stained nuclei (data not shown).

The percentage of stained nuclei and the weights of parathyroid glands were compared in the N-type and D-type, using the WilcoxonMann-Whitney test. The relationship between the percentage of stained nuclei and the weights of the parathyroid glands was examined by least squares method.

\section{Results}

Specificity of staining. Incubation of sections of human parathyroid glands with anti-VDR antibody revealed a pattern of nuclear localization with little cytoplasmic staining (Fig. $2 A$ ), that is, immunoreactivity was observed predominantly in the nuclei of parathyroid gland cells. Control sections incubated
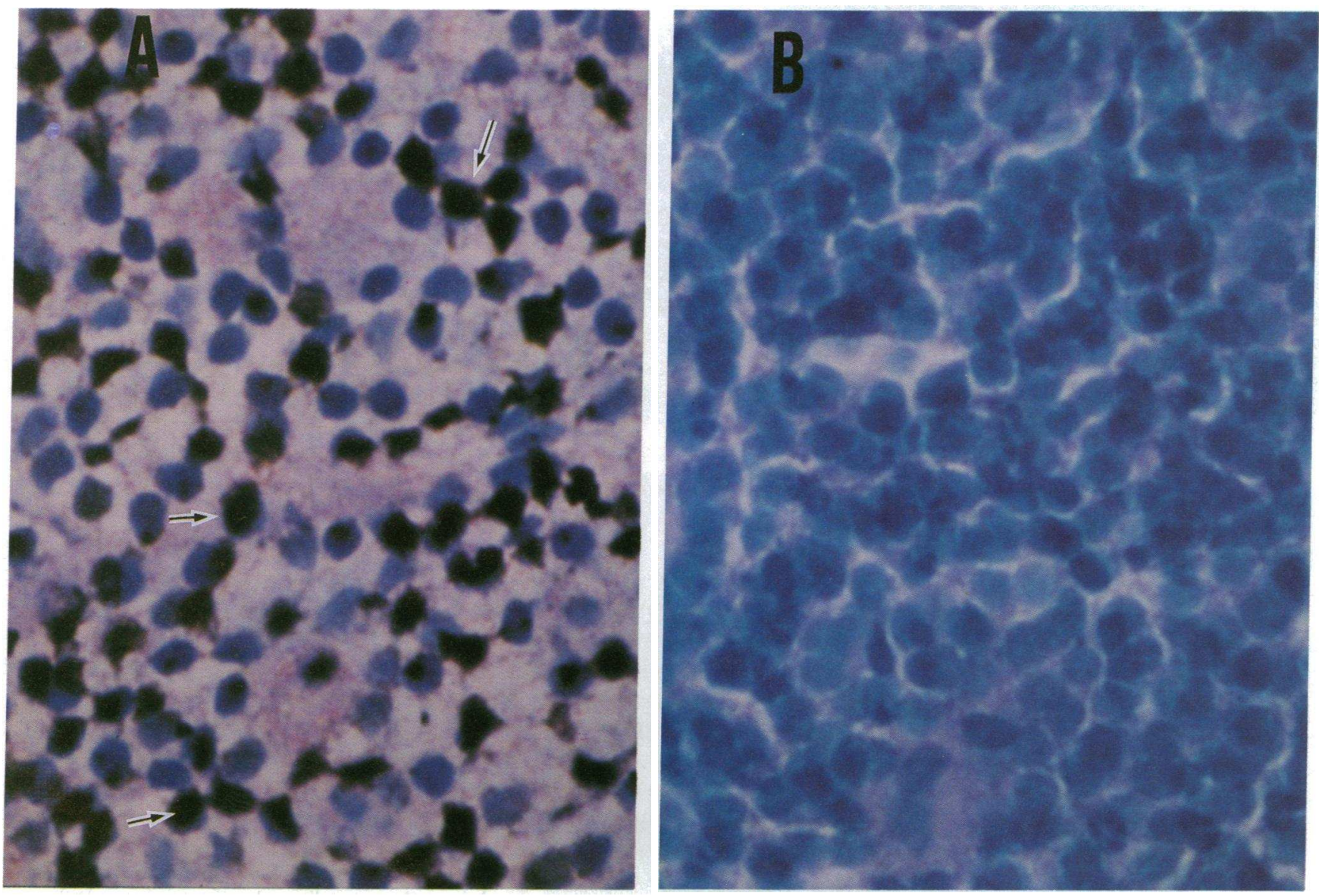

Figure 2. Immunohistochemical staining of VDR in hyperplastic parathyroid tissues (counterstain: methylene green) $\times 400$. $(A)$ Parathyroid cells stained with 9A7. Black nuclei (arrows) show positive VDR staining with little cytoplasmic staining. $(B)$ Parathyroid cells incubated without 9A7. These cells show only counterstained; i.e., blue nuclei. 
without 9A7 did not reveal any nuclear staining (Fig. $2 B$ ). The nuclear staining associated with $9 A 7$ was inhibited by preincubation of 9A7 with recombinant VDR.

$V D R$ immunohistochemical assay. VDR immunoreactivity was distributed homogeneously within the areas of diffuse hyperplasia. This distribution was also uniform within each of the nodules. Cells from tissue of the N-type demonstrated a marked decrease in nuclear staining compared with cells from tissue of the D-type (Fig. 3, $A$ and $B$ ). We determined the percentage of specifically stained nuclei. In the D-type, VDR immunoreactivity was expressed by $45.2 \pm 11.7 \%$ (mean \pm SD) of these cells and in the N-type, it was expressed by only $23.1 \pm 6.16 \%$ of the parathyroid cells, the percentage in the $\mathrm{N}$ type being significantly lower than that in the D-type ( $P$ $<0.01$ ) (Fig. 4).

Occasionally, different histological types of hyperplastic parathyroid glands were found to coexist in one 2HPT patient. Two parathyroid glands from one patient were found to be an N-type (percentage of VDR staining, 28.2\%) and a D-type (43.8\%), and four glands from another patient were found to be two N-type ( $21.6 \%$ and $33.6 \%$, respectively) and two D-type (32.3\% and $44.1 \%$, respectively). In these cases, the VDR density in the N-type was lower than that in the D-type.

Careful histological evaluation revealed small nodules in two D-type parathyroid glands. VDR immunoreactivity was virtually negative within such nodules, while cells outside the such nodules in the same section expressed positive staining (Fig. 5).

Relationship to PTH content. When the distribution of VDR immunoreactivity in parathyroid tissues is examined, it is necessary to show whether the parenchymal cells are actually stained. Therefore, we performed double staining using antibodies against VDR and PTH. The cytoplasm was stained for PTH in cells with nuclei that were positively stained for VDR, as well as in cells whose nuclei were negatively stained for VDR (Fig. 6). These findings suggest that nuclear staining associated with 9A7 is expressed in the parenchymal cells; we can thus exclude the possibility that the different distribution of stromal cells caused differences in the VDR density between the $\mathrm{N}$ - and D-types.

Relationship to weight of the parathyroid gland. The weights of three parathyroid glands were unknown; we examined the weight of 17 glands ( $12 \mathrm{~N}$-type and $5 \mathrm{D}$-type). The mean weight of the $\mathrm{N}$-type was $2,044 \pm 2,121.3 \mathrm{mg}$ ( range: 555 $8,111 \mathrm{mg}$ ) and the mean weight of the D-type was $340 \pm 213.8$ $\mathrm{mg}$ (range: $49-580 \mathrm{mg}$ ). The $\mathrm{N}$-type was significantly heavier than the D-type $(P<0.0003)$. Since $1,25(\mathrm{OH})_{2} \mathrm{D}_{3}$ is reported to be associated with the proliferation of parathyroid cells, we examined the relationship between the weight of the glands and VDR density. A comparison of the weights of the parathyroid
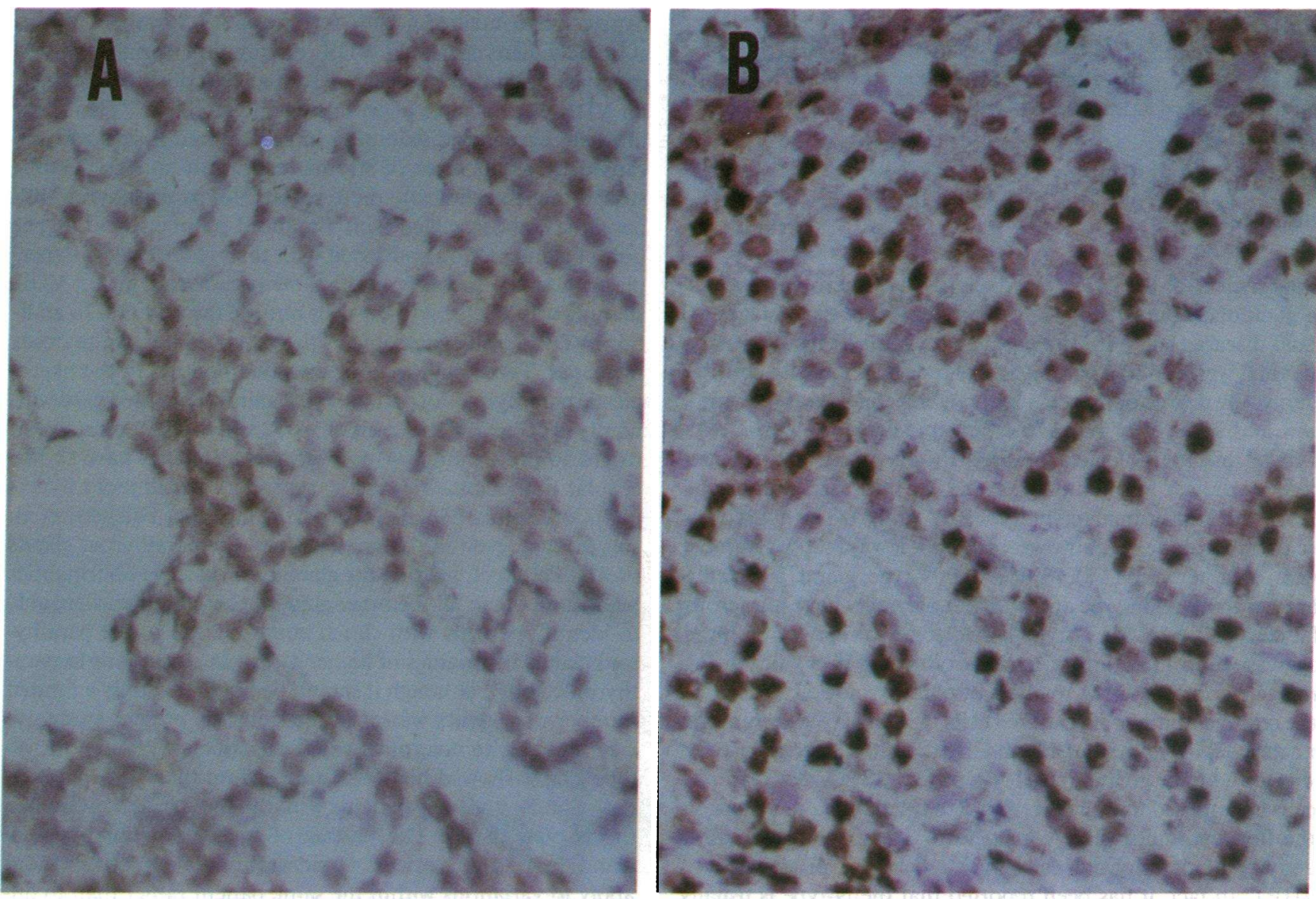

Figure 3. Comparison of diffuse and nodular hyperplastic parathyroids for immunohistochemical staining of VDR (counterstain: hematoxylin). $\times$ 400. ( $A$ ) Nodular hyperplastic parathyroid tissue section. $(B)$ Diffuse hyperplastic parathyroid tissue section. Positive staining of cells for VDR is clearly greater in diffuse hyperplasia than in the nodular form. 


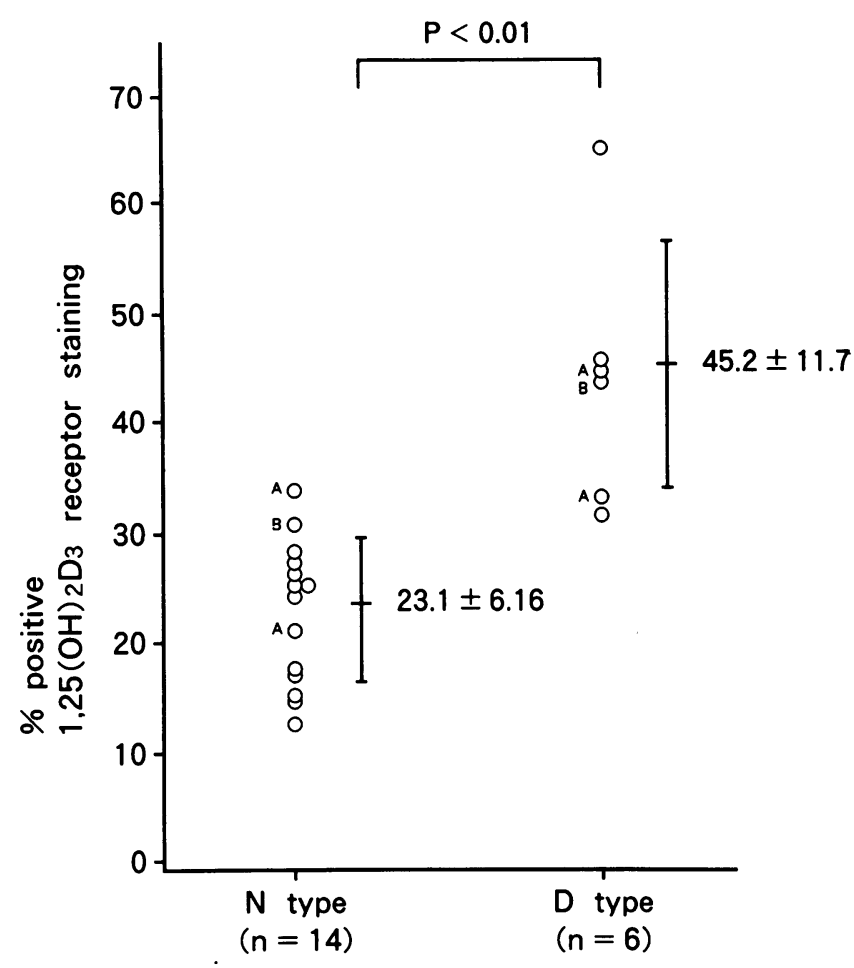

Figure 4. Percentage of VDR positive staining in the different types of hyperplasia. Open circles A and B indicate parathyroid glands excised from patients $A$ and $B$.

glands and the corresponding percentages of positive VDR staining revealed a significant negative correlation $(r=-0.573$, $P<0.02$ ) (Fig. 7).

\section{Discussion}

Enlargement of the parathyroid glands and microscopic signs of glandular abnormality may be seen even in early stages of renal disease (9). With the progression of renal insufficiency, the total weight of the parathyroid glands may increase considerably; the degree of this enlargement correlates with the duration and severity of renal function impairment $(9,10,16)$. Typical histopathological findings in advanced renal hyperparathyroidism are nodularities and an increased number of oxyphil or transitional oxyphil cells $(9,10,17)$. The hyperplastic parathyroid tissue, however, does not always show symmetrical enlargement (17). Since the $\mathrm{N}$-type gland is usually heavier than the D-type and does not normally have numerous fat cells $(10,17)$, the N-type is suspected to represent a more aggressive proliferation of parathyroid cells. In a study using image cytometric DNA analysis of parathyroid cells in 2HPT, the relative number of scattered cells that displayed cytometric nuclear DNA values outside the main diploid histogram peak was found to be greater in the $\mathrm{N}$-type $(12,18)$. These scattered cells is supposed to well correspond to fraction of the $S$ phase in the flow-cytometric DNA histogram. Thus, the proliferative activity of parathyroid cells may reflect the progression of 2HPT. In fact, it has been reported that the N-type is usually present in patients with higher concentrations of serum $\mathrm{COOH}$-terminal immunoreactive PTH and more severe bone symptoms (11). Therefore, this type is likely to represent the advanced stage of hyperplasia and to be present in more severe hyperparathyroidism.

Studies of the direct action of $1,25(\mathrm{OH})_{2} \mathrm{D}_{3}$ on parathyroid cells have shown that it suppresses the secretion (19-22) and synthesis $(2,6,23-28)$ of PTH and directly inhibits parathyroid cell proliferation (29-31).

At present, it is thought that resistance to the physiological concentration of serum $1,25(\mathrm{OH})_{2} \mathrm{D}_{3}$ in parathyroid cells occurs in hemodialysis patients with severe 2HPT (19-22). The resistance is considered to be caused, in part, by a VDR deficiency in the parathyroid glands. Korkor demonstrated that the parathyroid glands of patients with chronic renal failure contained almost one third of the receptors found in parathyroid adenomas (3). Merke et al. found that, in acutely uremic rats, $6 \mathrm{~d}$ after subtotal nephrectomy, the parathyroid glands contained only half the amount of receptor found in the parathyroid glands of sham-operated controls (4). Similar results were reported by Brown, et al. in chronically uremic dogs (5). These studies suggest that the reduced receptor number in the parathyroid glands of uremic patients may render the glands less responsive to the inhibitory action of $1,25(\mathrm{OH})_{2} \mathrm{D}_{3}$. However, there are also reports that showed no decrease in VDR in uremic rats $(6,7)$. These conflicting results may be caused by the use of biochemical procedures that depend on tissue homogenization and fractionation; thus, individual parts of the parathyroid containing heterogeneous types of tissues and cells cannot be distinguished.

Here, we demonstrated that even in the D-type gland, the hyperplasia contained nodule-forming areas, and there was an extremely heterogeneous VDR distribution. Immunohistochemical staining for PTH showed that cells positively stained for VDR were capable of producing and secreting PTH. Thus, this heterogeneous distribution in parathyroid tissues was not caused by an increase of stromal cells. Our studies demonstrated that the clinically more severe $\mathrm{N}$-type parathyroid hyperplasia was associated with a reduced number of VDR per unit of gland section compared with the milder D-type hyperplastic glands; especially in the same parathyroid gland, VDR staining was localized in the cells outside the nodules. In addition, VDR density decreased as the weight of the parathyroids increased. These findings indicated that nodules in the hyperplastic parathyroids of patients with uremia consisted predominantly of cells with low levels of VDR, which are hyperactive in regard to proliferation. Moreover, recent reports have shown cellular monoclonalities in the secondary parathyroid hyperplasia of uremia $(32,33)$. Of particular note, Falchetti et al. suggest that, even in the same patient, the parathyroid glands show different clonalities, the glands with clonal abnormalities being larger than all the other glands. These authors were able to identify patients with clonal abnormalities in the parathyroid glands by findings of higher serum calcium prior to parathyroidectomy, although it should be noted that only a limited number of patients was examined. In this present study, we were not able to determine whether patients with only the Ntype glands showed higher serum calcium than those with Dtype glands, since our patients with the D-type glands also had the N-type glands. The finding of totally different types of glands in the same patients would suggest that our observations apply to variations within the same patient rather than to differences from one patient to another. Our findings, taken together with those of Falchetti et al., thus suggest that decreased density of VDR in the parathyroid may underlie not only the 


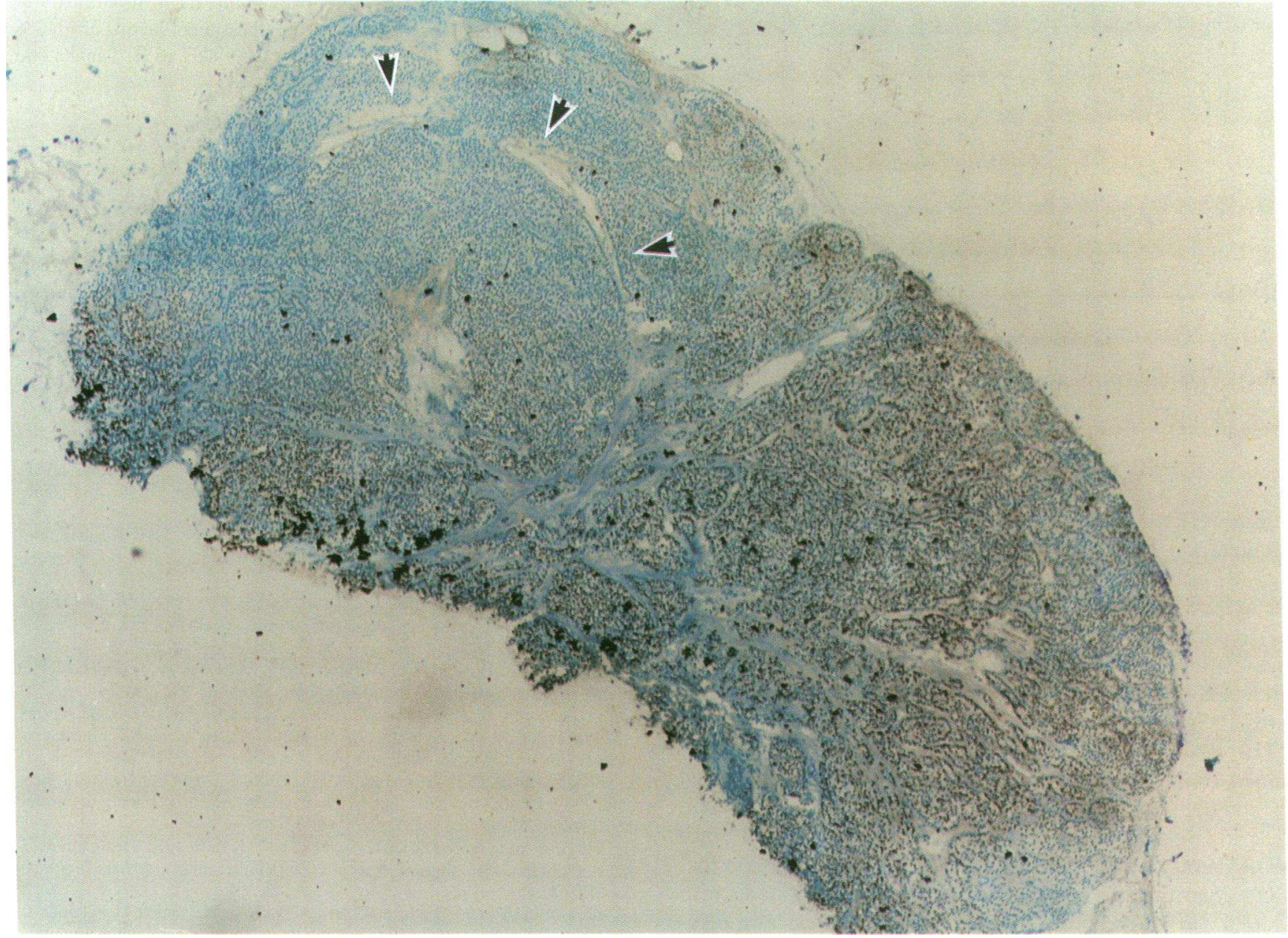

Figure 5. Immunohistochemical VDR staining in diffuse hyperplastic parathyroid tissue containing a small nodule (arrowheads). Positive VDR staining is found, predominantly, in the cells outside the nodule (counterstain: methylene green) $\times \times 400$.

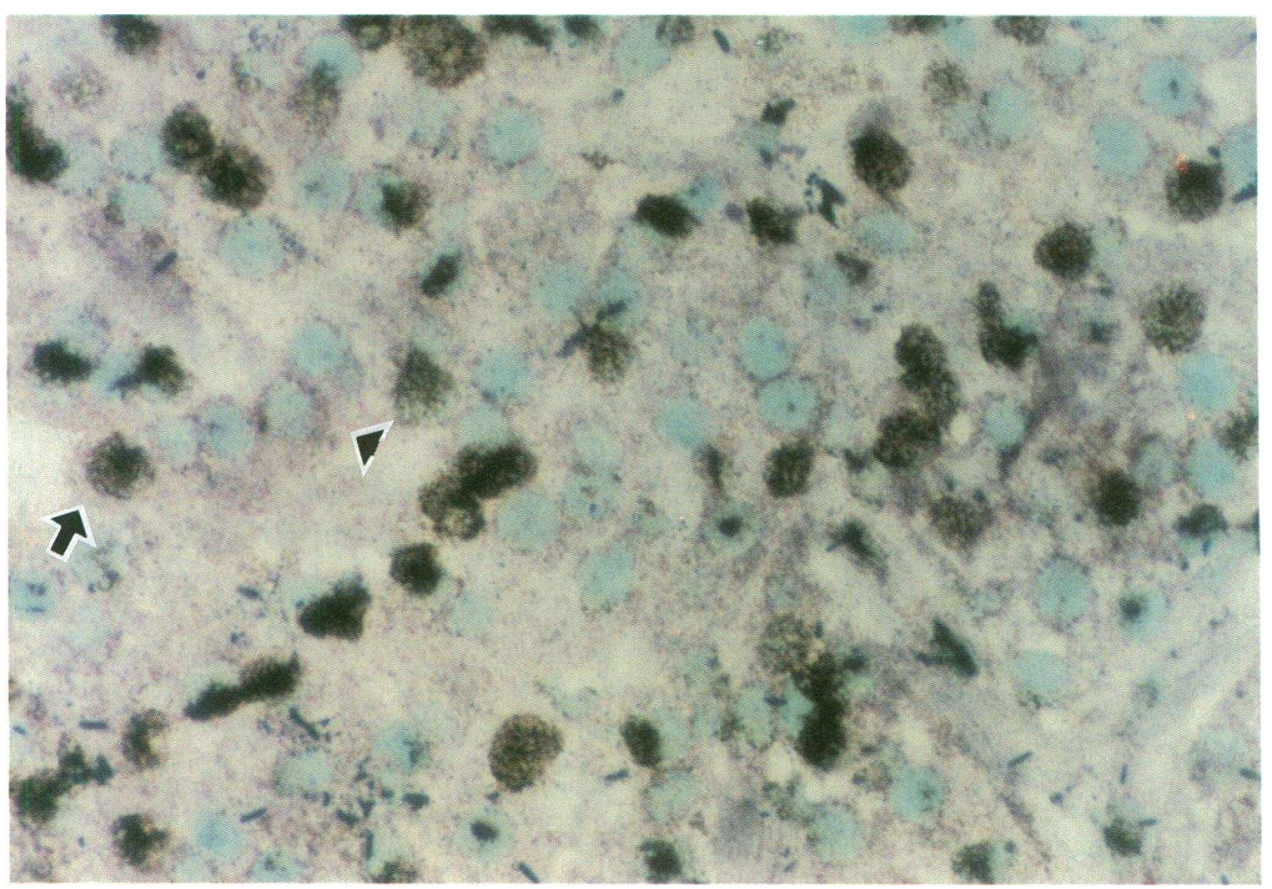

Figure 6. Double-staining for VDR and PTH in hyperplastic parathyroid tissue (counterstain: methylene green ). $\times 400$. PTH immunoreactivity appears violet in the cytoplasm of both VDR-positive (arrow) and VDR-negative cells (arrowhead). 


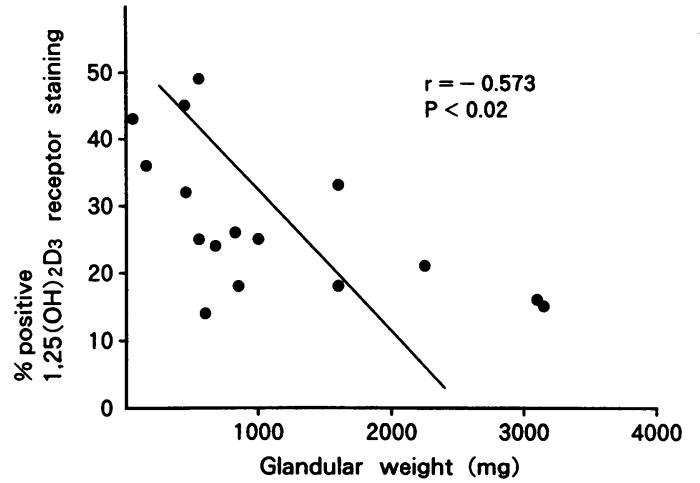

Figure 7. Distribution of percent positive staining for VDR in relation to weight of parathyroid glands. There is a negative correlation between percent VDR and glandular weight.

resistance to $1,25(\mathrm{OH})_{2} \mathrm{D}_{3}$ but also the clonal selection and proliferation of parathyroid cells in 2HPT. Further, it is likely that, with the progression of 2HPT, nodule formation within the D-type tissue may develop into the N-type.

In addition to the increases in the mass of parathyroid tissue, another important mechanism responsible for 2HPT in uremia is probably the shift in the set-point for calcium-regulated PTH secretion. It has been reported that the control of PTH release by calcium is abnormal in parathyroid cells obtained from nodules (34). A similar abnormality was indicated in nodules with numerous oxyphil and transitional oxyphil cells in hyperplastic parathyroid due to uremia (35). Since VDR density was decreased in the N-type, it is possible that VDR abnormalities in the parathyroid glands of patients with uremia play a role in the abnormal set point for calcium-regulated PTH secretion.

When parathyroid glands with changed cell constitution proliferate vigorously and show strong resistance to $1,25(\mathrm{OH})_{2} \mathrm{D}_{3}$ in the advanced stage of $2 \mathrm{HPT}$, parathyroidectomy may become necessary. Clinical findings have demonstrated that hemodialysis patients with large parathyroid glands respond poorly to calcitriol "pulse therapy" (36). It is thought that the efficacy of high dose calcitriol therapy depends, to a certain degree, on VDR density in the parathyroids and on parathyroid size.

In addition, the frequency of recurrent 2HPT after total parathyroidectomy with forearm autograft was shown to be higher when tissues of $\mathrm{N}$-type rather than D-type tissue remained (12). It is possible that decreased VDR density in autotransplanted parathyroid tissue is a factor in the graft-dependent recurrence of 2HPT after total parathyroidectomy with autograft.

We conclude that VDR density was decreased in parathyroid tissue showing nodular hyperplasia compared with that in diffuse hyperplasia. This decrease may contribute to the progression of 2HPT because of chronic renal failure and to the proliferation of parathyroid cells in uremia.

\section{Acknowledgments}

We would like to thank Dr. A. Tokunaga (Third Department of Anatomy, Okayama University) and Dr. Z. Ota (Third Department of Internal Medicine, Okayama University) for the technical suggestions and Rumi Abe-Nojima for her technical assistance.
This study was supported in part by grants from the Ministry of Health and Welfare and the Ministry of Education of Japan (02404036 to K. Kurokawa 04670598 to Y. Seino, 04807067 to H. Tanaka and 04670374 to M. Fukagawa).

\section{References}

1. Coburn, J. W., and E. A. Slatopolsky. 1991. The renal osteodystrophy. In The Kidney. B. M. Brenner and F. C. Rector, editors. W. B. Saunders Company, Philadelphia. p. 2058.

2. Fukagawa, M., S. Kaname, T. Igarashi, E. Ogata, and K. Kurokawa. 1991. Regulation of parathyroid hormone synthesis in chronic renal failure in rats. Kidney Int. 39:874-881.

3. Korkor, A. B. 1987. Reduced binding of $\left[\mathrm{H}^{3}\right] 1,25$-dihydroxyvitamin $\mathrm{D}_{3}$ in the parathyroid glands of patients with renal failure. N. Engl. J. Med. 316:15731577.

4. Merke, J., U. Hugel, A. Zlotkowski, A. Szabo, J. Bommer, G. Mall, and E. Ritz. 1987. Diminished parathyroid $1,25-(\mathrm{OH})_{2} \mathrm{D}_{3}$ receptor in experimental uremia. Kidney Int. 32:350-353.

5. Brown, A. J., A. Dusso, S. Lopez-Hilker, J. Lewis-Finch, P. Grooms, and E. Slatopolsky. 1989. 1,25( $\mathrm{OH})_{2} \mathrm{D}$ receptors are decreased in parathyroid glands from chronically uremic dogs. Kidney Int. 35:19-23.

6. Shvil, Y., T. Naveh-Many, P. Barach, and J. Silver. 1990. Regulation of parathyroid cell gene expression in experimental uremia. J. Am. Soc. Nephrol. 1:99-104.

7. Szabo, A., J. Merke, M. Thomasset, and E. Ritz. 1991. No decrease of $1,25(\mathrm{OH})_{2} \mathrm{D}_{3}$ receptors and duodenal calbindin- $\mathrm{D}_{9 k}$ in uraemic rats. Eur. J. Clin. Invest. 21:521-526.

8. Krause, M. W., and C. E. Hedinger. 1985. Pathologic study of parathyroid glands in tertiary hyperparathyroidism. Hum. Pathol. 16:772-784.

9. Akerstrom, G., J. Malmaeus, L. Grimelius, S. Ljunghall, and R. Bergstrom. 1984. Histological changes in parathyroid glands in subclinical and clinical renal disease. An autopsy investigation. Scand. J. Urol. Nephrol. 18:75-84.

10. Malmaeus, J., L. Grimelius, H. Johansson, G. Akerstrom, and S. Ljunghall. 1984. Parathyroid pathology in hyperparathyroidism secondary to chronic renal failure. Scand. J. Urol. Nephrol. 18:157-166.

11. Tominaga, Y., H. Takagi, H. Suzuki, and T. Kondo. 1985. Histopathological study of parathyroid gland in renal hyperparathyroidism. J. Jpn. Surg. Soc. 86:630-639.

12. Tominaga, Y., Y. Tanaka, K. Sato, M. Numao, K. Uchida, U. Falkmer, L. Grimelius, H. Johansson, and H. Takagi. 1992. Recurrent renal hyperparathyroidism and DNA analysis of autografted parathyroid tissue. World J. Surg. 16:595-603.

13. Pike, J. W. 1984. Monoclonal antibodies to chick intestinal receptors for 1,25-dihydroxyvitamin $\mathrm{D}_{3}$. J. Biol. Chem. 259:1167-1173.

14. Sone, T., D. P. McDonnell, B. W. O'Malley, and W. Pike. 1990. Expression of human vitamin D receptor in Saccharomyces. J. Biol. Chem. 265:2199722003.

15. Finch, J. L., N. Rapp, K. J. Martin, and E. Slatopolsky. 1992. A new sensitive homologous radioimmunoassay for amino-terminal parathyroid hormone in the rat. J. Bone Miner. Res. 7:229-233.

16. Hellman, P., G. Akerstrom, S. Ljunghall, and J. Rastad. 1989. Surgical findings and results of subtotal and total parathyroidectomy in hypercalcemic patients with uremic hyperparathyroidism. Acta Chir. Scand. 155:573-582.

17. Takagi, H., Y. Tominaga, K. Uchida, N. Yamada, K. Kawasaki, and H. Suzuki. 1983. Polymorphism of parathyroid glands in patients with chronic renal failure and secondary hyperparathyroidism. Endocrinol. Jpn. 30:463-468.

18. Tominaga, Y., L. Grimelius, U. G. Falkmer, H. Johansson, and S. Falkmer. 1991. DNA ploidy pattern of parathyroid parenchymal cells in renal secondary hyperparathyroidism with relapse. Anal. Cell Pathol. 3:325-333.

19. Slatopolsky, E., C. Weerts, J. Thielan, R. Horst, H. Harter, and K. J. Martin. 1984. Marked suppression of secondary hyperparathyroidism by intravenous administration of 1,25-dihydroxycholecalciferol in uremic patients. J. Clin. Invest. 74:2136-2143.

20. Chan, Y. L., C. McKay, E. Dye, and E. Slatopolsky. 1986. The effect of 1,25-dihydroxycholecalciferol on parathyroid hormone secretion by monolayer cultures of bovine parathyroid cells. Calcif. Tissue. Int. 38:27-32.

21. Delmez, J. A., C. Tindira, P. Grooms, A. Dusso, D. W. Windus, and E. Slatopolsky. 1989. Parathyroid hormone suppression by intravenous 1,25-dihydroxyvitamin D. A role for increased sensitivity to calcium. J. Clin. Invest. 83:1349-1355.

22. Dunlay, R., M. Rodriguez, A. J. Felsenfeld, and F. Llach. 1989. Direct inhibitory effect of calcitriol on parathyroid function (sigmoidal curve) in dialysis. Kidney Int. 36:1093-1098.

23. Heinrich, G., H. M. Kronenberg, and J. T. Potts. 1983. Parathyroid hormone messenger ribonucleic acid: effect of calcium on cellular regulation in vitro. Endocrinology. 112:449-458.

24. Silver, J., J. Russell, and L. M. Sherwood. 1985. Regulation by vitamin D 
metabolites of messenger ribonucleic acid for preproparathyroid cells. Proc. Natl. Acad. Sci. USA. 82:4270-4273.

25. Cantley, L. K., J. Russell, D. Lettieri, and L. M. Sherwood. 1985. 1,25-Dihydroxyvitamin $D_{3}$ suppresses PTH secretion from bovine parathyroid cells in tissue culture. Endocrinology. 227:2114-2119.

26. Russell, J., D. Lettieri, and L. M. Sherwood. 1986. Suppression by 1,25$(\mathrm{OH})_{2} \mathrm{D}_{3}$ of transcription of the parathyroid hormone gene. Endocrinology. 119:2864-2866.

27. Silver, J., T. Naveh-Many, H. Mayer, H. J. Schmelzer, and M. M. Popovtzer. 1986. Regulation by vitamin D metabolites of parathyroid hormone gene transcription in vivo in the rat. J. Clin. Invest. 78:1296-1301.

28. Okazaki, T., T. Igarashi, and H. M. Kronenberg. 1988. 5 '-Flanking region of parathyroid hormone gene mediates negative regulation by $1,25(\mathrm{OH})_{2}$ vita$\operatorname{minD}_{3}$. J. Biol. Chem. 263:2203-2208.

29. Nygren, P., R. Larsson, H. Johansson, S. Rastad, and G. Akerstrom. 1988. $1,25(\mathrm{OH})_{2} \mathrm{D}_{3}$ inhibits hormone secretion and proliferation but not functional dedifferentiation of cultured bovine parathyroid cells. Calcif. Tissue Int. 43:213218.

30. Kremer, R., I. Bolivar, D. Goltzman, and G. N. Hendy. 1989. Influence of calcium and 1,25-dihydroxycholecalciferol on proliferation and proto-oncogene expression in primary cultures of bovine parathyroid cells. Endocrinology. 125:935-941.

31. Szabo, A., J. Merke, E. Beier, G. Mall, and E. Ritz. 1989. 1,25(OH) $)_{2}$ vitaminD $\mathrm{D}_{3}$ inhibits parathyroid cell proliferation in experimental uremia. Kidney Int. 35:1049-1056.

32. Falchetti, A., A. E. Bale, A. Amorosi, C. Bordi, P. Cicchi, S. Bradini, S. J. Marx, and M. L. Brandi. 1993. Progression of uremic hyperparathyroidism involves allelic loss on chromosome 11. J. Clin. Endocrinol. \& Metab. 76:139-144.

33. Arnold, A., M. Brown, P. Urena, T. Drueke, and E. Sarfati. 1992. X-inactivation analysis of clonality in primary and secondary parathyroid hyperplasia. (Abstr.) J. Bone Miner. Res. 7(Suppl. 1):241.

34. Wallfelt, C. H., R. Larsson, E. Gylfe, S. Ljunghall, J. Rastad, and G. Akerstrom. 1988. Secretory disturbance in hyperplastic parathyroid nodules of uremic hyperparathyroidism: implication for parathyroid autotransplantation. World J. Surg. 12:431-438.

35. Juhlin, C., J. Rastad, L. Klareskog, L. Grimelius, and G. Akerstrom. 1989. Parathyroid histology and cytology with monoclonal antibodies recognizing a calcium sensor of parathyroid cells. Am. J. Pathol. 135:321-328.

36. Kitaoka, M., M. Fukagawa, Y. Tanaka, E. Ogata, and K. Kurokawa. 1991. Parathyroid gland size is critical for long-term prognosis of calcitriol pulse therapy in chronic dialysis patients. (Abstr.) J. Am. Soc. Nephrol. 2:637. 